\title{
Histamine formation by mouse preimplantation embryos
}

\author{
S. K. Dey and D. C. Johnson \\ Departments of Obstetrics \& Gynecology and Physiology, Ralph L. Smith Research Center, \\ University of Kansas Medical Center, Kansas City, Kansas 66103, U.S.A.
}

\begin{abstract}
Summary. Mouse embryos recovered on the 4th day of pregnancy produced histamine, as evidenced by the ${ }^{14} \mathrm{CO}_{2}$ produced from carboxy labelled L-histidine, at the rate of $1.5 \pm 0.3$ (s.e.m.) pmol/embryo per hour. Most $(83.2 \pm 4.6 \%)$ of the embryos flushed from the oviducts on Day 3 of pregnancy (4-8-cell stage) developed into blastocysts within $48 \mathrm{~h}$ after being placed in culture. Inclusion of L-histidine hydrochloride $\left(4.7 \times 10^{-4} \mathrm{M}\right)$ in the culture medium did not alter this development but DL- $\alpha$-methylhistidine $\left(3.8 \times 10^{-4} \mathrm{M}\right)$, an inhibitor of histidine decarboxylase, reduced the number of embryos developing into blastocysts to only $10.8 \pm 6.8 \%$. A combination of L-histidine and DL- $\alpha$-methylhistidine in the medium prevented the growth-retarding effect of the latter compound. The results indicate that mouse embryos can produce histamine and suggest that this is necessary for normal development.
\end{abstract}

\section{Introduction}

Recent observation suggests that rabbit blastocysts are capable of forming histamine and that interference with this function interrupts embryo development and implantation (Dey, Johnson \& Santos, 1979). The aim of the present study was to determine (1) whether mouse preimplantation embryos are also able to form histamine and (2) the effects of inhibition of histidine decarboxylase activity on preimplantation embryo development in culture.

\section{Materials and Methods}

Outbred female mice of the Charles River strain (CD-1) were mated by males of the Swiss-Webster strain. The morning of finding the vaginal plug was designated as Day 1 of pregnancy.

\section{Histidine decarboxylase (HDC) assay}

Mice induced to superovulate by treatment with gonadotrophins (Fowler \& Edwards, 1957) were killed on the morning (09:00-10:00 h) of Day 4 of pregnancy. The preimplantation embryos were recovered by flushing the entire reproductive tract with Whitten's medium (Whitten, 1971) and washed four times in the same medium. The embryos from several mice were pooled and distributed at random to several batches. HDC (EC 4.1.1.22) assays were run in batches of 10-77 embryos per tube for $3 \mathrm{~h}$ under an atmosphere of $90 \% \mathrm{~N}_{2}+5 \% \mathrm{CO}_{2}+5 \%$ $\mathrm{O}_{2}$ by a method essentially similar to that described for rabbit blastocysts (Dey et al., 1979). The only exception was that culture medium rather than buffer was used to adjust the total volume of 
each tube to $250 \mu$ l. Specificity of HDC activity was examined by incubating the embryos for $1 \mathrm{~h}$ before and during the assay in the presence of a specific inhibitor of HDC, DL- $\alpha$-methylhistidine dihydrochloride (DL- $a-\mathrm{MH}$; Sigma Chemical Co., St Louis, Missouri) (Hammar \& Ragnarsson, 1979). Tests with boiled homogenates of rabbit blastocysts and rat fetal and gastric mucosa tissues showed that the results were similar to those obtained by using buffer alone (Dey et al., 1979). In the present study, therefore, tubes without embryos were run concurrently with the experimental tubes and the blank values were subtracted: the amount of ${ }^{14} \mathrm{CO}_{2}$ formed in tubes containing embryos was at least twice that found in blank tubes. The enzyme activity is expressed as pmol $\mathrm{CO}_{2}$ evolved/embryo per $h$.

\section{Culture of embryos}

Mice were killed on the morning ( $08: 00 \mathrm{~h}$ ) of Day 3 of pregnancy. Embryos ( $4-8$ cells) were recovered by flushing the oviducts with Whitten's medium under sterile conditions. The embryos were pooled from several animals, washed four times in the same medium and divided into several batches (10-20 embryos/ml/tube) for culture. They were cultured for $48 \mathrm{~h}$ by the method described by Whitten (1971) and then embryonic development was examined under a microscope. The embryos were cultured in the presence of (1) L-histidine hydrochloride (Sigma Chemical Co.), the substrate for HDC, (2) DL- $a-\mathrm{MH}$, an inhibitor for this enzyme, or (3) a combination of the two. The concentrations of these substances were determined from the results of preliminary experiments. Batches of embryos cultured in the medium alone were always included with the experimental tubes in each experiment to serve as controls.

\section{Embryo transfer}

To determine the effects of the agents used upon the development of the embryos to the blastocyst stage, some of the embryos which reached the blastocyst stage were transferred (8-10 blastocysts/mouse) to Day-4 pseudopregnant mice $(\mathrm{N}=5)$, produced by sterile matings with vasectomized males. The young were examined at birth and observed until after weaning.

\section{Results}

Most of the embryos recovered on the morning of Day 4 were blastocysts $(76.2 \pm 1.7 \%)$ and the remainder were late morulae. Therefore, HDC activity was expressed per embryo regardless of the stage. The mean \pm s.e.m. enzyme activity in 7 experiments (10-50 embryos/experiment) was $1.5 \pm 0.3 \mathrm{pmol} / \mathrm{embryo} / \mathrm{h}$. Increasing the number of embryos to $10-50$ embryos per assay showed increases in HDC activity in a linear fashion. However, inclusion of 70 or more embryos in an assay produced a $67.4 \pm 6.5 \%$ ( 3 tests, $70-77$ embryos/test) reduction in activity. HDC activity in the embryos exposed to $0.83 \mathrm{mM}$-DL- $\alpha$-MH was only about $30 \%$ of that in control embryos i.e. showed a $71.5 \pm 2.8 \%$ reduction ( 3 tests, $19-33$ embryos/test).

As shown in Table 1, the numbers of 4-8-cell embryos developing to the blastocyst stage in medium alone or containing L-histidine were not altered, but the addition of the higher concentration of DL- $\alpha-\mathrm{MH}$ drastically retarded development. Most of the embryos were arrested at or before the compacted morula stage. When L-histidine and DL- $\alpha$-MH were included in the culture medium, embryonic development was normal.

Eighteen blastocysts cultured in the medium only and transferred to 2 foster mothers gave birth to 10 healthy offspring (6/10 and 4/8). Similar transfer of 29 blastocysts, cultured in the presence of L-histidine $\left(4.7 \times 10^{-4} \mathrm{M}\right)$ and $\mathrm{DL}-\alpha-\mathrm{MH}\left(3.8 \times 10^{-4} \mathrm{M}\right)$ to 3 pseudopregnant mice produced 13 healthy young $(5 / 10,5 / 10$ and $3 / 9)$. 
Table 1. The effect of an inhibitor of histidine decarboxylase upon mouse preimplanation embryo development (mean \pm s.e.m.) in vitro

\begin{tabular}{|c|c|c|c|c|}
\hline Treatment & $\begin{array}{l}\text { No. of } \\
4-8 \text {-cell } \\
\text { embryos } \\
\text { cultured* }\end{array}$ & $\%$ blastocysts & $\%$ morulae & $\%$ undeveloped \\
\hline Medium alone & $116(10)$ & $83 \cdot 2 \pm 4 \cdot 6^{a}$ & $6 \cdot 5 \pm 4 \cdot 1^{a}$ & $10 \cdot 3 \pm 4 \cdot 1^{a}$ \\
\hline L-Histidine $\left(4.7 \times 10^{-4} \mathrm{M}\right)$ & $116(10)$ & $84 \cdot 8 \pm 4 \cdot 0^{\mathrm{a}}$ & $10 \cdot 8 \pm 4 \cdot 4^{a, b}$ & $4.4 \pm 1 \cdot 5^{\mathrm{a}}$ \\
\hline DL- $\alpha-M H\left(1.9 \times 10^{-4} M\right)$ & $41(5)$ & $56 \cdot 0 \pm 18 \cdot 7^{\mathrm{a}}$ & $28 \cdot 6 \pm 18 \cdot 2^{\mathrm{a}, \mathrm{b}}$ & $15 \cdot 4 \pm 15 \cdot 4^{a}$ \\
\hline DL- $\alpha-M H\left(3.8 \times 10^{-4} M\right)$ & $100(10)$ & $10.8 \pm 6.8^{\circ}$ & $31 \cdot 0 \pm 9 \cdot 6^{b}$ & $58 \cdot 1 \pm 11 \cdot 6^{\mathrm{b}}$ \\
\hline $\begin{array}{l}\text { L-Histidine }\left(4.7 \times 10^{-4} \mathrm{M}\right)+ \\
\quad \text { DL- } \alpha \text {-MH }\left(3.8 \times 10^{-4} \mathrm{M}\right)\end{array}$ & $86(7)$ & $89 \cdot 0 \pm 5 \cdot 5^{\mathrm{a}}$ & $8 \cdot 2 \pm 4 \cdot 2^{\mathrm{a}}$ & $2.9 \pm 2.9^{\mathrm{a}}$ \\
\hline
\end{tabular}

* Numbers in parentheses indicate number of experiments. Means with the same superscript letter are not significantly $(P>0.05)$ different from each other (Student's $t$ test).

\section{Discussion}

The results suggest that the mouse Day-4 preimplantation embryo is able to form histamine. When this activity is expressed in terms of the average protein content of a mouse embryo (20.4 ng: Brinster, 1967), it is much higher than that of other mammalian tissues (Dey et al., 1979). That the synthesis of this amine is related to some physiological function is indicated by the observation that when Day 3 (4-8-cell) embryos were exposed for $48 \mathrm{~h}$ to DL- $\alpha$-MH they failed to develop to the blastocyst stage. However, our study does not determine the ontogeny, the developmental pattern of HDC in the embryo, or the precise stage of the development when the embryos require histamine synthesis. The prevention by histidine of the inhibition produced by DL- $\alpha$-MH suggests that the retarded development was due to suppression of embryonic HDC activity, rather than to some non-specific action of the chemical. The birth of healthy young following transfer of these blastocysts to pseudopregnant mice also indicates normal development of the embryos under this condition.

The reduction of HDC activity by increasing the number of embryos to 70 or more in the assay mixture follows the same pattern as was observed with rabbit blastocysts (Dey et al., 1979). The presence of an 'inhibitor' of HDC in rabbit blastocysts was suggested and this may be a common feature of mammalian preimplantation embryos.

Very little information is available about the role of histamine synthesis in the mammalian preimplantation embryo and more study will be required to elucidate its role in embryo development and metabolism. However, a few possibilities could be considered. Firstly, the histamine-forming capacity that is observed in the preimplantation embryo could have simply a growth-promoting function. A role for histamine in fetal development has been suggested (Kahlson, 1962). Alternatively, histamine may exert its influence via synthesis of prostaglandins in the embryo. This amine has been shown to stimulate phospholipase $A_{2}$ activity which then increases the level of fatty acid precursor in tissues for prostaglandin synthesis (references in Dey \& Johnson, 1980). Bovine (Shemesh, Milaguir, Ayalon \& Hansel, 1979) and rabbit (Dey, Chien, Cox \& Crist, 1980) blastocysts are reported to synthesize prostaglandins, and Biggers, Leonov, Baskar \& Fried (1978) suggest that prostaglandins may be responsible for blastocyst expansion and hatching of the zona pellucida in vitro. However, further investigation is required to elucidate whether a relationship exists between histamine and prostaglandins as it relates to embryonic development and whether histamine synthesis in the mouse blastocysts plays any role in implantation. 
We thank Miss Cheri Cox for technical assistance. This research was supported by NICHD grant (HD-12304).

\section{References}

Biggers, J.D., Leonov, B.V., Baskar, J.F. \& Fried, J. (1978) Inhibition of hatching of mouse blastocysts in vitro by prostaglandin antagonists. Biol. Reprod. 19, 519-533.

Brinster, R.L. (1967) Protein content of the mouse embryo during the first five days of development. J. Reprod. Fert. 13, 413-420.

Dey, S.K. \& Johnson, D.C. (1980) Re-evaluation of histamine in implantation. In The Endometrium, pp. 269-283. Ed. F. Kimball. Spectrum Publications, New York.

Dey, S.K., Johnson, D.C. \& Santos, J.G. (1979) Is histamine production by the blastocyst required for implantation in the rabbit? Biol. Reprod. 21, 11691174.

Dey, S.K., Chien, S.M., Cox, C.L. \& Crist, R.D. (1980) Prostaglandin synthesis in the rabbit blastocyst. Prostaglandins 19, 449-453.
Fowler, R.E. \& Edwards, R.G. (1957) Induction of superovulation and pregnancy in mature mice by gonadotropins. J. Endocr. 15, 374-384.

Hammar, L. \& Ragnarsson, U. (1979) Peptide inhibition of mammalian histidine decarboxylase. Agents and Actions 9, 314-318.

Kahlson, G. (1962) New approaches to the physiology of histamine. Perspect. Biol. Med. 5, 179-197.

Shemesh, M., Milaguir, F., Ayalon, N. \& Hansel, W. (1979) Steroidogenesis and prostaglandin synthesis by cultured bovine blastocysts. J. Reprod. Fert. 56, 181-185.

Whitten, W.K. (1971) Nutrient requirements for the culture of preimplantation embryos in vitro. $A d v$. Biol. Sci. 6, 129-141.

Received 28 April 1980 